Check for updates

Cite this: RSC Adv., 2018, 8, 30223
Received 28th July 2018 Accepted 22nd August 2018

DOI: $10.1039 / \mathrm{c} 8 \mathrm{ra0} 6356 \mathrm{~g}$

rsc.li/rsc-advances

\section{Novel SrLaAlO $4: \mathrm{Mn}^{4+}$ deep-red emitting phosphors with excellent responsiveness to phytochrome $P_{F R}$ for plant cultivation LEDs: synthesis, photoluminescence properties, and thermal stability}

\author{
K. Sankarasubramanian, ${ }^{a}$ Balaji Devakumar, ${ }^{a}$ G. Annadurai, ${ }^{a}$ Liangling Sun, ${ }^{a}$ \\ Yu-Jia Zeng (D) ${ }^{* b}$ and Xiaoyong Huang (D) *a
}

\begin{abstract}
Herein, novel rare-earth-free $\mathrm{Mn}^{4+}$-doped $\mathrm{SrLAIO}_{4}$ deep-red emitting phosphors were successfully synthesized via a traditional solid-state reaction method. The crystal structure and phase purity of the asprepared samples were confirmed by XRD Rietveld refinement. Photoluminescence properties of SrLaAlO $: \mathrm{Mn}^{4+}$ phosphors were examined in detail using photoluminescence spectra, decay lifetimes, temperature-dependent emission spectra and internal quantum efficiency measurements. The excitation spectrum obtained by monitoring at $730 \mathrm{~nm}$ contained two excitation bands centered at 364 and $520 \mathrm{~nm}$ within the range of $200-550 \mathrm{~nm}$ due to the $\mathrm{Mn}^{4+}-\mathrm{O}^{2-}$ charge-transfer band and the ${ }^{4} \mathrm{~A}_{2 \mathrm{~g}} \rightarrow$ ${ }^{4} \mathrm{~T}_{1 \mathrm{~g}},{ }^{4} \mathrm{~T}$ 2g transitions of the $\mathrm{Mn}^{4+}$ ions. Under the $364 \mathrm{~nm}$ excitation, the $\mathrm{SrLaAl}_{4}: \mathrm{Mn}^{4+}$ phosphors exhibited an intense deep-red emission band in $610-790 \mathrm{~nm}$ wavelength range peaking at $730 \mathrm{~nm}$, which was assigned to the ${ }^{2} \mathrm{E}_{g} \rightarrow{ }^{4} \mathrm{~A}_{2 g}$ transition of $\mathrm{Mn}^{4+}$ ions. The deep red emission showed excellent responsiveness to phytochrome $\mathrm{PFR}_{\mathrm{FR}}$, revealing that the $\mathrm{SrLaAlO}_{4}: 0.4 \% \mathrm{Mn}^{4+}$ phosphors possessed a possible application in deep-red light-emitting diodes (LEDs) for plant cultivation. The optimal doping concentration of $\mathrm{Mn}^{4+}$ ions was found to be $0.4 \mathrm{~mol} \%$. The critical distance $R_{\mathrm{c}}$ for energy transfer among $\mathrm{Mn}^{4+}$ ions was determined to be $5.86 \AA$ and the concentration quenching mechanism was confirmed to be the electric dipole-dipole interaction. In addition, the Commission International de I'Eclairage (CIE) colour coordinates of the $\mathrm{SrLaAlO}_{4}: 0.4 \% \mathrm{Mn}^{4+}$ phosphors $(0.734,0.266)$ were located in the deep red region and the corresponding internal quantum efficiency was measured to be about $29 \%$. The above results confirmed that the as-prepared $\mathrm{SrLaAlO}_{4}: 0.4 \% \mathrm{Mn}^{4+}$ deep red emitting phosphors might be a potential candidate for plant cultivation LEDs.
\end{abstract}

\section{Introduction}

Inorganic phosphors with outstanding optical properties have been broadly used over the past decades in many applications, such as, solid-state lighting, displays, optical temperature sensors, solar cells, and plant cultivation. ${ }^{1-15}$ Currently, lightemitting diodes (LEDs) are used as light sources for indoor plant cultivation in the agricultural area, which leads to improved plant cultivation within a natural atmosphere (e.g., light, water, air, temperature, and growth media). ${ }^{16-18}$ Artificial light sources are important for indoor plant cultivation to enhance the growth of plant tissues. The absorption spectra of

${ }^{a}$ Key Lab of Advanced Transducers and Intelligent Control System, Ministry of Education and Shanxi Province, College of Physics and Optoelectronics, Taiyuan University of Technology, Taiyuan 030024, P. R. China. E-mail: huangxy04@126.com ${ }^{b}$ Shenzhen Key Laboratory of Laser Engineering, College of Optoelectronic Engineering, Shenzhen University, Shenzhen 518060, P. R. China. E-mail: yjzeng@szu.edu.cn photosynthesis pigments like chlorophyll and carotenoid match well with the light sources of blue and red LEDs. It has been reported that blue light with the wavelength of 410$500 \mathrm{~nm}$ affects the growth of chlorophyll, leaf morphogenesis, flower-bud formation, stomatal opening, and phototropism, and red light with the wavelength of $610-700 \mathrm{~nm}$ may be supportive to develop the vegetative flowering, budding, and internodal elongation, while the far-red light around $730 \mathrm{~nm}$ promotes the plant cultivation and photosynthesis. ${ }^{19-22}$ Hence, it is essential to find alternative high colour purity red or deep red emitting phosphors.

$\mathrm{Eu}^{3+}$ and $\mathrm{Sm}^{3+}$ doped red phosphors are widely used in many fields, but their limitations in LEDs applications are mainly due to their sharp absorption peaks in ultraviolet (UV) and blue regions; and moreover, most of rare earth ions are costly. In addition, $\mathrm{Eu}^{2+}$ doped oxynitrides and nitrides based red phosphors also have some unavoidable deficiencies in practical applications caused by their critical synthesis process, because 
high temperature and high pressure are needed for their preparation..$^{23-27}$ In recent years, many researchers intended to find eco-friendly non-rare-earth ions activated red-emitting phosphors. Compared with $\mathrm{Eu}^{3+}$ and $\mathrm{Sm}^{3+}$ doped red phosphors, $\mathrm{Mn}^{4+}$ ions activated phosphors show several important advantages, such as strong excitation peak at 300 to $480 \mathrm{~nm}$ and strong emission in the range from 600 to $780 \mathrm{~nm}$, economically cheap and no absorption in green spectral range. ${ }^{12,28-32} \mathrm{Mn}^{4+}$ ions could be suitable activators for replacing the $\mathrm{Al}^{3+}, \mathrm{Ti}^{4+}, \mathrm{Zr}^{4+}$, $\mathrm{Si}^{4+}$ or $\mathrm{Ge}^{4+}$ sites in the host materials and give rise to red or deep red emissions originating from spin-forbidden ${ }^{2} \mathrm{E}_{\mathrm{g}} \rightarrow{ }^{4} \mathrm{~A}_{2 \mathrm{~g}}$ transition of $\mathrm{Mn}^{4+}$ ions. The $\mathrm{Mn}^{4+}$ activated fluorides usually display red emissions around 620-640 $\mathrm{nm}$ because of their weak hybridization effect. In sharp contrast, $\mathrm{Mn}^{4+}$ activated oxide materials generally exhibit deep-red emissions with wavelengths longer than $650 \mathrm{~nm}$ owing to their strong hybridization effect. In recent years, many researchers investigated the $\mathrm{Mn}^{4+}$ activated oxide-based phosphors due to their chemical stability and eco-friendly synthesis process. ${ }^{33-46}$

In this work, we reported on novel deep red emitting $\mathrm{Mn}^{4+}$ activated $\mathrm{SrLaAlO}_{4}$ phosphors prepared by using conventional high-temperature solid-state reaction method. The crystal structure, morphology, and luminescence properties of $\mathrm{SrLaAlO}_{4}$ :$\mathrm{Mn}^{4+}$ phosphors were investigated in detail. The $\mathrm{SrLaAlO}_{4}$ compound crystallizes in tetragonal structure with the space group of $I 4 / \mathrm{mmm}$. In $\mathrm{SrLaAlO}_{4}$ host, $\mathrm{Al}^{3+}$ ion is octahedrally coordinated with six oxygens, and thus $\mathrm{Mn}^{4+}$ ions would occupy $\mathrm{Al}^{3+}$ sites in $\mathrm{SrLaAlO}_{4}$ host lattice due to their close ionic radii. Under $364 \mathrm{~nm}$ near-UV excitation, the $\mathrm{SrLaAlO}_{4}: \mathrm{Mn}^{4+}$ phosphors exhibited deep red emission in the 650-800 $\mathrm{nm}$ wavelength range peaking at $730 \mathrm{~nm}$, which matched well with the absorption spectra of phytochrome $\mathrm{P}_{\mathrm{FR}}$. The optimal doping concentration of $\mathrm{Mn}^{4+}$ ions was $0.4 \mathrm{~mol} \%$, and the corresponding internal quantum efficiency (IQE) of the $\mathrm{SrLaAlO}_{4}: 0.4 \% \mathrm{Mn}^{4+}$ phosphor was found to be about $29 \%$. Finally, a deep-red LED device was fabricated by coating the as-prepared $\mathrm{SrLaAlO}_{4}: 0.4 \% \mathrm{Mn}^{4+}$ phosphors on the surface of a $365 \mathrm{~nm}$ InGaN LED chip. The results demonstrated the $\mathrm{SrLaAlO}_{4}: \mathrm{Mn}^{4+}$ phosphors could be new non-rare-earth-based red emitting luminescence materials for applications in plant cultivation LEDs.

\section{Experimental}

The $\mathrm{SrLaAl}_{1-x} \mathrm{O}_{4}: x \mathrm{Mn}^{4+}$ (abbreviated as SLA: $x \mathrm{Mn}^{4+}: x=0.1 \%$, $0.2 \%, 0.4 \%, 0.6 \%, 0.8 \%$ and $1 \%$ ) phosphors with various $\mathrm{Mn}^{4+}$ doping concentrations were prepared via solid-state reaction method. The $\mathrm{SrCO}_{3}$ (analytical reagent, A.R.), $\mathrm{La}_{2} \mathrm{O}_{3}$ (99.99\%), $\mathrm{Al}_{2} \mathrm{O}_{3}$ (A.R.), and $\mathrm{MnCO}_{3}$ (A.R.) were used as the source materials of $\mathrm{Sr}, \mathrm{La}, \mathrm{Al}$ and $\mathrm{Mn}$, respectively. According to the stoichiometric ratio, the $\mathrm{SrCO}_{3}, \mathrm{La}_{2} \mathrm{O}_{3}, \mathrm{Al}_{2} \mathrm{O}_{3}$ and $\mathrm{MnCO}_{3}$ were weighed and the mixture was ground thoroughly using an agate mortar. Then, this uniform mixture was placed in an alumina crucible and sintered at $1500{ }^{\circ} \mathrm{C}$ for $6 \mathrm{~h}$ in air atmosphere. Finally, the product was allowed to cool down to room temperature, and re-ground for further characterization.

The crystal system of SLA: $\mathrm{Mn}^{4+}$ phosphors were characterized using powder X-ray diffraction (XRD) pattern (Bruker D8
Advance, $\mathrm{CuK} \alpha$ radiation). Rietveld refinement of the prepared sample was performed by the FULLPROF software. The surface morphological and elemental mapping of the SLA:0.4\% $\mathrm{Mn}^{4+}$ phosphors were performed using a field-emission scanning electron microscope (FE-SEM; MAIA3 TESCAN). The roomtemperature photoluminescence (PL) and photoluminescence excitation (PLE) as well as decay curves were recorded using Edinburgh FS5 spectrofluorometer equipped with a $150 \mathrm{~W}$ continuous-wavelength xenon lamp and a pulsed xenon lamp as the excitation source, respectively. The IQE measurement was achieved by using Edinburgh FS5 spectrofluorometer equipped with an integrating sphere coated with barium sulphate. The temperature-dependent emission spectra were measured by using Edinburgh FS5 spectrofluorometer in the range of 303$483 \mathrm{~K}$ and the temperature was tuned by the temperature controlling system.

\section{Results and discussion}

The phase purity and crystalline nature of the as-prepared SLA:0.4\% $\mathrm{Mn}^{4+}$ phosphors were examined using XRD. Fig. 1 shows the XRD patterns of pure SLA and $0.4 \% \mathrm{Mn}^{4+}$ doped SLA phosphors. It can be seen that all diffraction peaks matched well with standard data of SLA (JCPDS card 24-1125), which belongs to the tetragonal crystal system. ${ }^{47}$ Any other crystalline phase was not observed after the doping of $\mathrm{Mn}^{4+}$ ions. The inclusion of $\mathrm{Mn}^{4+}$ ion into the SLA lattice did not induce any significant change on the crystal system of the host because of their similar valence and ionic radii of $\mathrm{Al}^{3+}(r=0.535 \AA)$ and $\mathrm{Mn}^{4+}(r=0.530 \AA)$ ions. ${ }^{48,49}$ The radius percentage value of SLA: $0.4 \% \mathrm{Mn}^{4+}$ phosphors was calculated using the formula: ${ }^{50}$

$$
D_{\mathrm{r}}=\frac{R_{\mathrm{m}}(\mathrm{CN})-R_{\mathrm{d}}(\mathrm{CN})}{R_{\mathrm{m}}(\mathrm{CN})} \times 100 \%
$$

where $D_{\mathrm{r}}$ radius percentage difference and CN denotes coordination number, $R_{\mathrm{m}}$ and $R_{\mathrm{d}}$ represent the ionic radii of host

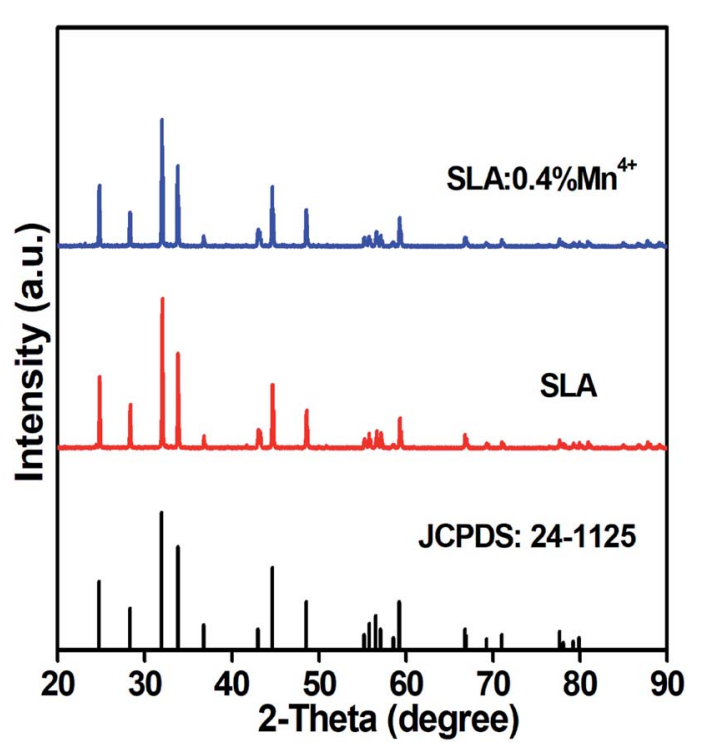

Fig. 1 XRD patterns of pure SLA and $0.4 \% \mathrm{Mn}^{4+}$ doped SLA phosphors. 
cation and doped ion, respectively. The radius percentage value of $\mathrm{Al}^{3+} / \mathrm{Mn}^{4+}$ was $0.9 \%$, which was smaller than $30 \%$. Furthermore, an acceptable percentage difference in ionic radii between doped and substituted ions must not exceed $30 \%$, which means that it is possible for $\mathrm{Mn}^{4+}$ ion enter into the $\mathrm{Al}^{3+}$ sites due to the similar radius $\left(\mathrm{Mn}^{4+}\right.$ and $\left.\mathrm{Al}^{3+}\right)$. It is impracticable for $\mathrm{Mn}^{4+}$ ions to substitute $\mathrm{La}^{3+}$ due to the large difference between the ionic radii of $\mathrm{Mn}^{4+}(r=0.530 \AA)$ and $\mathrm{La}^{3+}(r=1.032$ A). 51

Fig. 2(a) shows the observed (black rounds), calculated (solid line), and different (bottom) XRD profiles for the Rietveld refinement of SLA:0.4\% $\mathrm{Mn}^{4+}$ phosphors. From the XRD pattern, all the diffraction peaks were effectively indexed by tetragonal crystal system with the space group of $14 / \mathrm{mmm}$. For SLA:0.4\% $\mathrm{Mn}^{4+}$ phosphors, the lattice parameter values were calculated to be $a=b=3.75545 \AA, c=12.63941 \AA$ and $V=$ $178.258 \AA^{3}$ and the refinement finally converged to $R_{\mathrm{p}}=8.97 \%$ and $R_{\mathrm{wp}}=11.34 \%$, indicating the refined atom, peak position and fraction factors obeyed the reflection conditions. Fig. 2(b) shows the schematic diagram of the SLA:0.4\% $\mathrm{Mn}^{4+}$ structure in tetragonal crystal system, in which $\mathrm{Sr}$ or $\mathrm{Al}$ atoms are coordinated by six $\mathrm{O}$ atoms, belonging to octahedral symmetry.

Fig. 3(a) represents the FE-SEM image of the SLA:0.4\% $\mathrm{Mn}^{4+}$ phosphors. The particles were aggregated with irregular morphology. Approximately the size of the particles was in micrometer range. Meanwhile, the elemental mapping result confirmed that the $\mathrm{Sr}, \mathrm{La}, \mathrm{Al}, \mathrm{O}$ and $\mathrm{Mn}$ elements were uniformly distributed throughout the particles, as indicated in Fig. 3(b-f).

Fig. 4(a) shows the PLE and PL spectra of SLA:0.4\% $\mathrm{Mn}^{4+}$ phosphors. The PLE spectrum monitored at $730 \mathrm{~nm}$ contained two broad excitation bands in the range of 250-550 nm, which could be well fitted by Gaussian peaks centered at 335, 381, 455 and $519 \mathrm{~nm}$ corresponding to the $\mathrm{Mn}^{4+}-\mathrm{O}^{2-}$ charge transfer band, the ${ }^{4} \mathrm{~A}_{2 \mathrm{~g}} \rightarrow{ }^{4} \mathrm{~T}_{1 \mathrm{~g}},{ }^{4} \mathrm{~A}_{2 \mathrm{~g}} \rightarrow{ }^{2} \mathrm{~T}_{2 \mathrm{~g}}$ and ${ }^{4} \mathrm{~A}_{2 \mathrm{~g}} \rightarrow{ }^{4} \mathrm{~T}_{2 \mathrm{~g}}$ transitions of $\mathrm{Mn}^{4+}$ ions. Under the $364 \mathrm{~nm}$ excitation, the obtained PL spectrum showed an intense emission band in the deep red range of $650-800 \mathrm{~nm}$ peaking at $730 \mathrm{~nm}$, corresponding to the ${ }^{2} \mathrm{E}_{\mathrm{g}} \rightarrow{ }^{4} \mathrm{~A}_{2 \mathrm{~g}}$ vibronic transition of $\mathrm{Mn}^{4+}$ ions. ${ }^{52,53}$ In Fig. 4(b), the


Fig. 2 (a) Rietveld refinement XRD patterns of SLA:0.4\% $\mathrm{Mn}^{4+}$ phosphors by the FULLPROF program. The solid black rounds, red lines and blue lines express the observed and calculated XRD patterns of the sample as well as their differences. The short vertical pink lines display the positions of Bragg reflection. (b) Schematic crystal structure of SLA: $0.4 \% \mathrm{Mn}^{4+}$ phosphors.

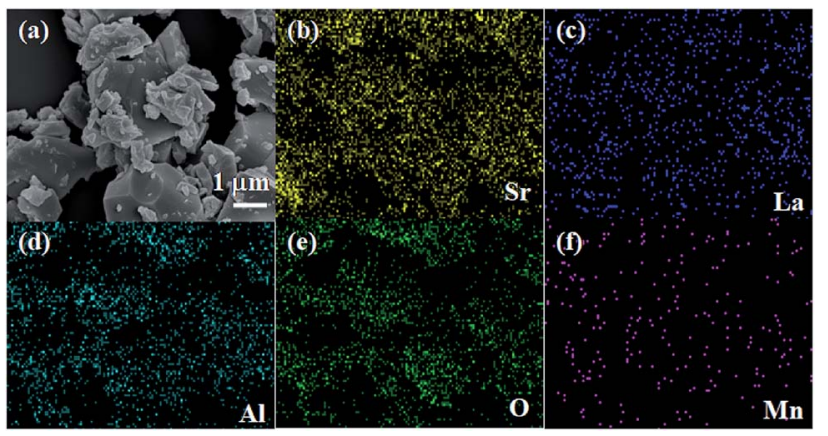

Fig. 3 (a) FE-SEM image and (b-f) elemental mapping of SLA:0.4\% $\mathrm{Mn}^{4+}$ phosphors.

PL spectrum of SLA:0.4\% $\mathrm{Mn}^{4+}$ phosphors was compared with the absorption spectra of phytochrome $\mathrm{P}_{\mathrm{R}}$ and $\mathrm{P}_{\mathrm{FR}}$. The absorption spectrum of phytochrome $\mathrm{P}_{\mathrm{FR}}$ was centered at about $730 \mathrm{~nm}$. Obviously a considerable overlap was found between the emission spectrum of SLA:0.4\% $\mathrm{Mn}^{4+}$ phosphors and the absorption spectrum of phytochrome $\mathrm{P}_{\mathrm{FR}}$, which confirmed that the SLA:0.4\% $\mathrm{Mn}^{4+}$ phosphor might be used for indoor plant cultivation as far-red emitting light source.

Fig. 5(a) shows the room-temperature PL spectra of SLA: $x \mathrm{Mn}^{4+}$ phosphors with different $\mathrm{Mn}^{4+}$ concentrations under the excitation of $364 \mathrm{~nm}$. It can be examined that all the emission peak positions and shapes have no noticeable change with altering $\mathrm{Mn}^{4+}$ ion concentration except the intensity. Fig. 5(b) shows the PL intensity as a function of $\mathrm{Mn}^{4+}$ doping concentration in SLA: $x \mathrm{Mn}^{4+}$ phosphors. It was obvious that, the PL intensity of $\mathrm{Mn}^{4+}$ increased at first, until it reached the maximum at $x=0.4 \%$, then it decreased slowly with increasing doping concentration, which was attributed to the concentration quenching effect. The decrease in PL intensity with increasing $\mathrm{Mn}^{4+}$ doping concentration may be due to the increase in nonradioactive decay, which was more possible beyond the optimal doping concentration. It has identified that the energy transfer is inversely proportional to $R_{\mathrm{n}}$, where $R$ is the distance between the neighbouring $\mathrm{Mn}^{4+}$ ions, and then the $R_{\mathrm{c}}$ could be calculated from the concentration quenching data. The $R_{\mathrm{c}}$ between $\mathrm{Mn}^{4+}$ ions can be calculated using the following formula: ${ }^{54}$

$$
R_{\mathrm{c}} \approx 2\left(\frac{3 V}{4 \pi x_{\mathrm{c}} Z}\right)^{1 / 3}
$$

where $R_{\mathrm{c}}$ is the critical distance, $V$ is the volume of the unit cell, $x_{\mathrm{c}}$ refers to the critical doping concentration and $Z$ is the number of sites available for the dopant in the unit cell. Herein, $x_{\mathrm{c}}=0.4 \% ; \mathrm{V}$ $=178.258 \AA^{3}$; and $Z=6$. Therefore, the $R_{\mathrm{c}}$ value of phosphors was calculated to be about $35.48 \AA$. This $R_{\mathrm{c}}$ value of $\mathrm{Mn}^{4+}$ doped SLA was higher than $5 \AA$, so that the exchange interaction mechanism was impossible between the $\mathrm{Mn}^{4+}$ ion. Therefore, the concentration quenching was mostly influenced by the electric multipolar interaction among $\mathrm{Mn}^{4+}$ ions as follows:

$$
\frac{I}{x}=k\left[1+\beta(x)^{\theta / 3}\right]^{-1}
$$

where $I$ is the emission intensity; $x$ is concentration of $\mathrm{Mn}^{4+}$ ions; $k$ and $\beta$ are constants for the given host; $\theta$ is a function of 

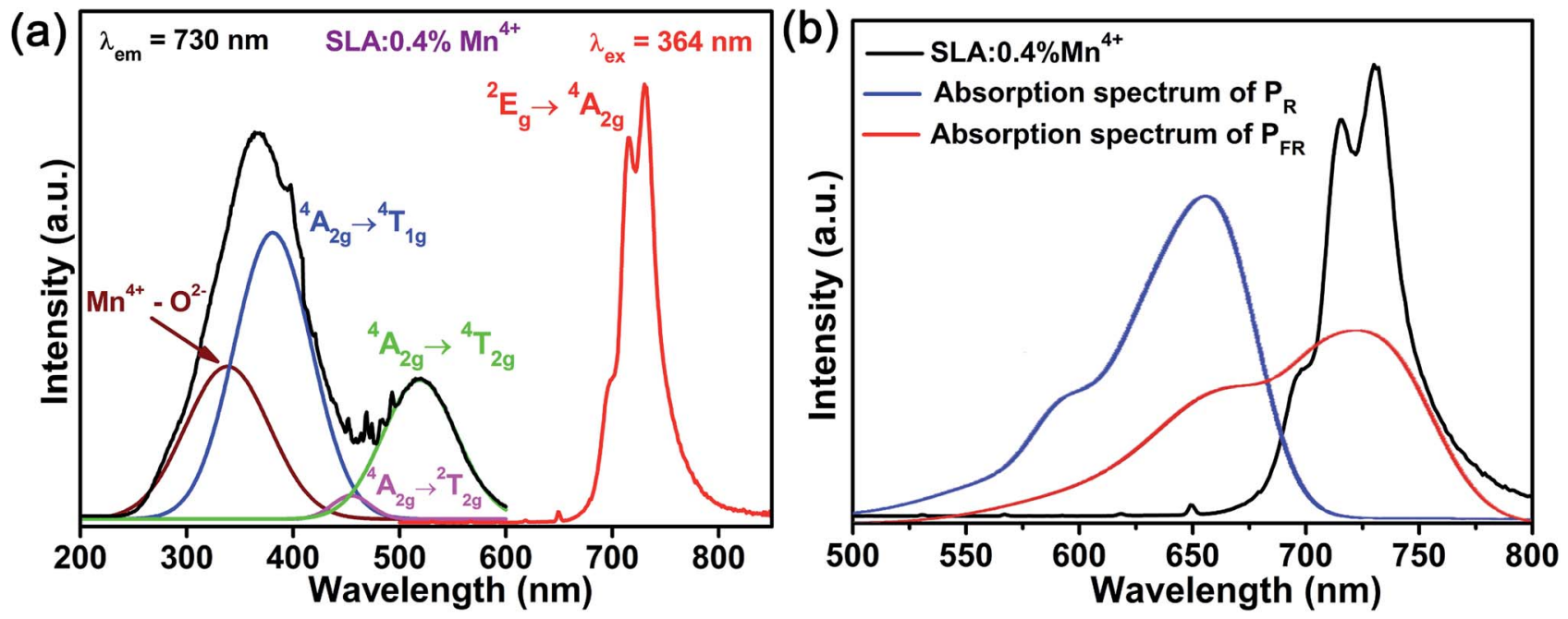

Fig. 4 (a) Room-temperature PLE and PL spectra of SLA:0.4\% $\mathrm{Mn}^{4+}$ phosphors. (b) PL spectrum of SLA:0.4\% Mn ${ }^{4+}$ phosphors and the absorption spectra of phytochrome $P_{F R}$ and $P_{R}$.

multipolar interaction, where $\theta=6,8$ and 10 stands for the dipole-dipole $(\mathrm{d}-\mathrm{d})$, dipole-quadrupole $(\mathrm{d}-\mathrm{q})$, quadrupolequadrupole $(\mathrm{q}-\mathrm{q})$ interactions, respectively.$^{55}$ Fig. $5(\mathrm{c})$ elucidates the relationship between $\log (x)$ versus $\log (I / x)$, which can be well fitted by a straight line with a slope of -1.89 . Hence, the $\theta$ value was calculated to be 5.67 , which was close to 6 . Thus the
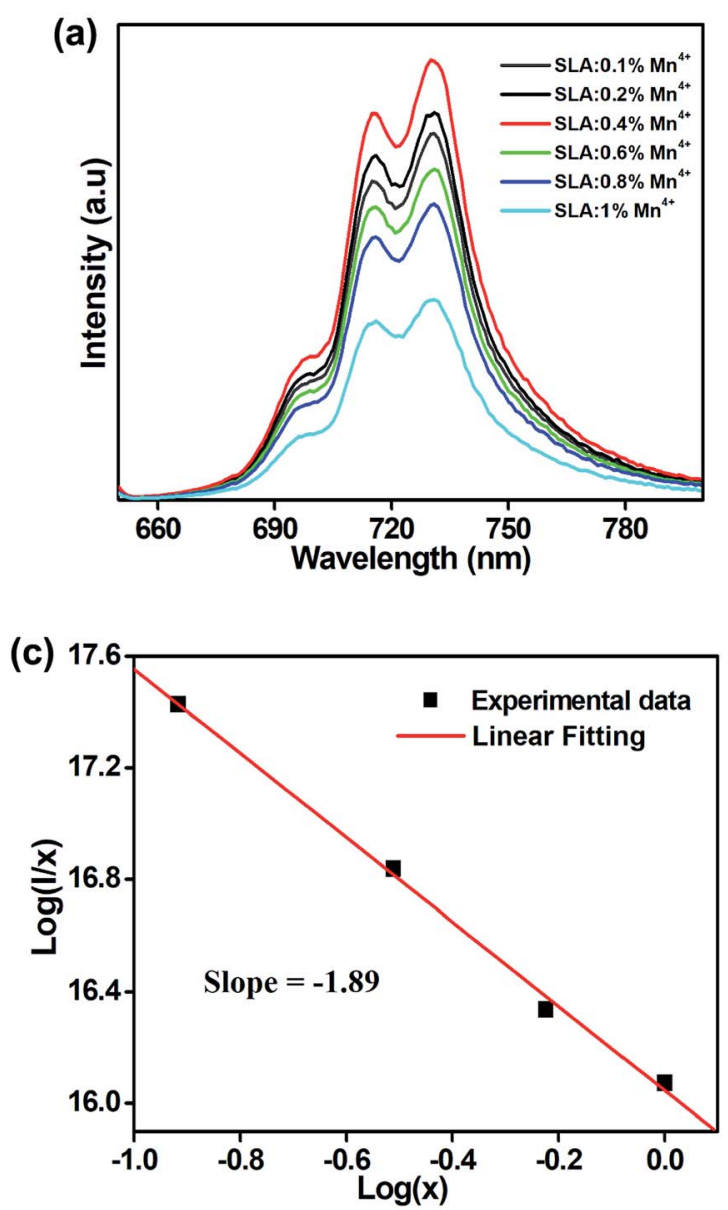
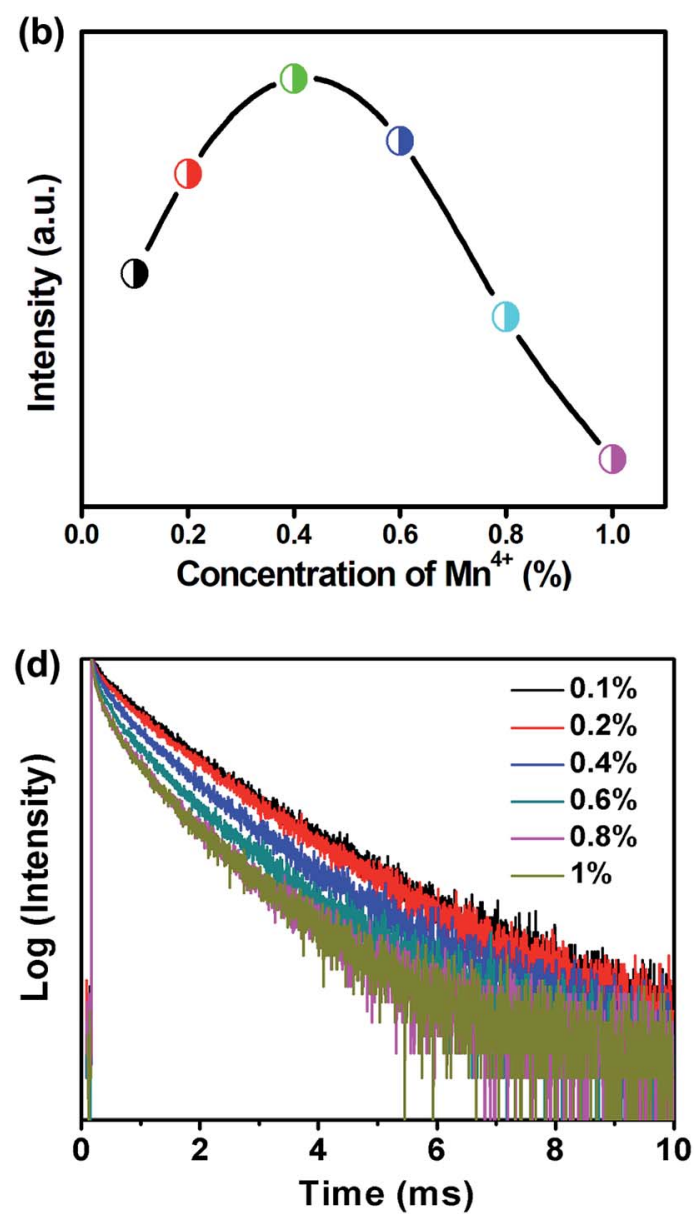

Fig. 5 (a) PL spectra of SLA: $x \mathrm{Mn}^{4+}(x=0.1 \%, 0.2 \%, 0.4 \%, 0.6 \%, 0.8 \%$, and $1 \%)$ phosphors as a function of $\mathrm{Mn}^{4+}$ doping concentrations. (b) $\mathrm{PL}$ emission intensities with $\mathrm{Mn}^{4+}$ doping concentration. (c) The relationship between $\log (/ / x)$ versus $\log (x)$. (d) PL decay curves and calculated lifetime values of SLA: $0.4 \% \mathrm{Mn}^{4+}$ phosphors under the excitation of $364 \mathrm{~nm}$ and monitored at $730 \mathrm{~nm}$. 
concentration quenching mechanism was dominant by the $\mathrm{d}-$ $\mathrm{d}$ interaction in SLA: $\mathrm{Mn}^{4+}$ phosphors.

Fig. 5(d) shows the concentration-dependent PL decay curves of SLA: $x \mathrm{Mn}^{4+}(x=0.1 \%, 0.2 \%, 0.4 \%, 0.6 \%, 0.8 \%$, and $1 \%)$ phosphors monitored at $730 \mathrm{~nm}$ under the excitation of $364 \mathrm{~nm}$. The PL decay curves were fitted by a single exponential decay equation:

$$
I(t)=I_{0}+A \exp (-t / \tau)
$$

where $I(t)$ is the emission intensities at $t, I_{0}$ represents the initial emission intensities, $\tau$ is the lifetime and $A$ is the constant. The estimated lifetime values were about 1.65, 1.35, 1.19, 1.08, 0.96, and $0.92 \mathrm{~ms}$ for various $\mathrm{Mn}^{4+}$ concentrations of $x=0.1 \%, 0.2 \%$, $0.4 \%, 0.6 \%, 0.8 \%$ and $1 \%$, respectively. The values of decay lifetime of SLA: $x \mathrm{Mn}^{4+}$ phosphors decreased with increasing of $\mathrm{Mn}^{4+}$ doping concentrations. The decrease of lifetime values may be due to the decrease in distance between $\mathrm{Mn}^{4+}$ ions with increase of $\mathrm{Mn}^{4+}$ concentration, the enhanced possibility of more frequent energy transfer between $\mathrm{Mn}^{4+}$ ions with increasing of $\mathrm{Mn}^{4+}$ concentration and the increase in nonradioactive transition probability. ${ }^{56-58}$

CIE coordinates are very essential to reveal that the exact emission and colour purity of the sample. Fig. 6 illustrates the CIE chromaticity diagram of SLA: $0.4 \% \mathrm{Mn}^{4+}$ phosphors with the excitation of $364 \mathrm{~nm}$. The CIE coordinate values of the SLA:0.4\% $\mathrm{Mn}^{4+}$ phosphors were calculated to be $(0.734,0.266)$, which located in the deep red region. The inset of Fig. 6 shows the digital image of the SLA:0.4\% $\mathrm{Mn}^{4+}$ phosphors under the excitation of $365 \mathrm{~nm}$ UV-lamp.

IQE value of SLA:0.4\% $\mathrm{Mn}^{4+}$ phosphors with the excitation of $364 \mathrm{~nm}$ was measured using an integrating sphere. The IQE value can be calculated using the following equation: ${ }^{59}$

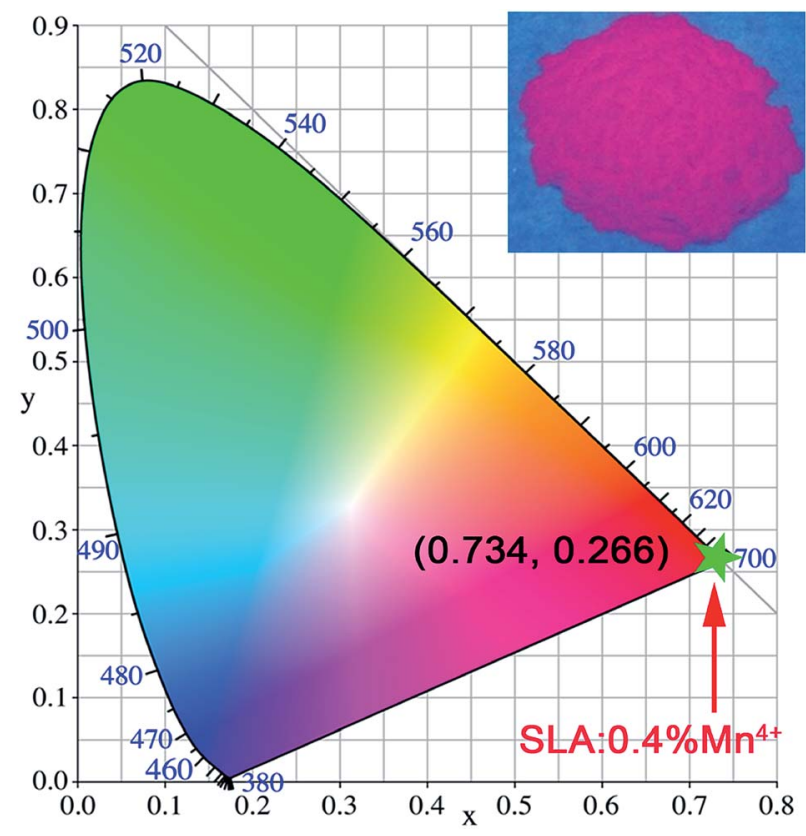

Fig. $6 \mathrm{CIE}$ chromaticity coordinates of SLA: $0.4 \% \mathrm{Mn}^{4+}$ phosphors $\left(\lambda_{\text {ex }}\right.$ $=364 \mathrm{~nm}$ ). Inset shows the image of SLA: $0.4 \% \mathrm{Mn}^{4+}$ phosphors under $365 \mathrm{~nm}$ UV lamp.
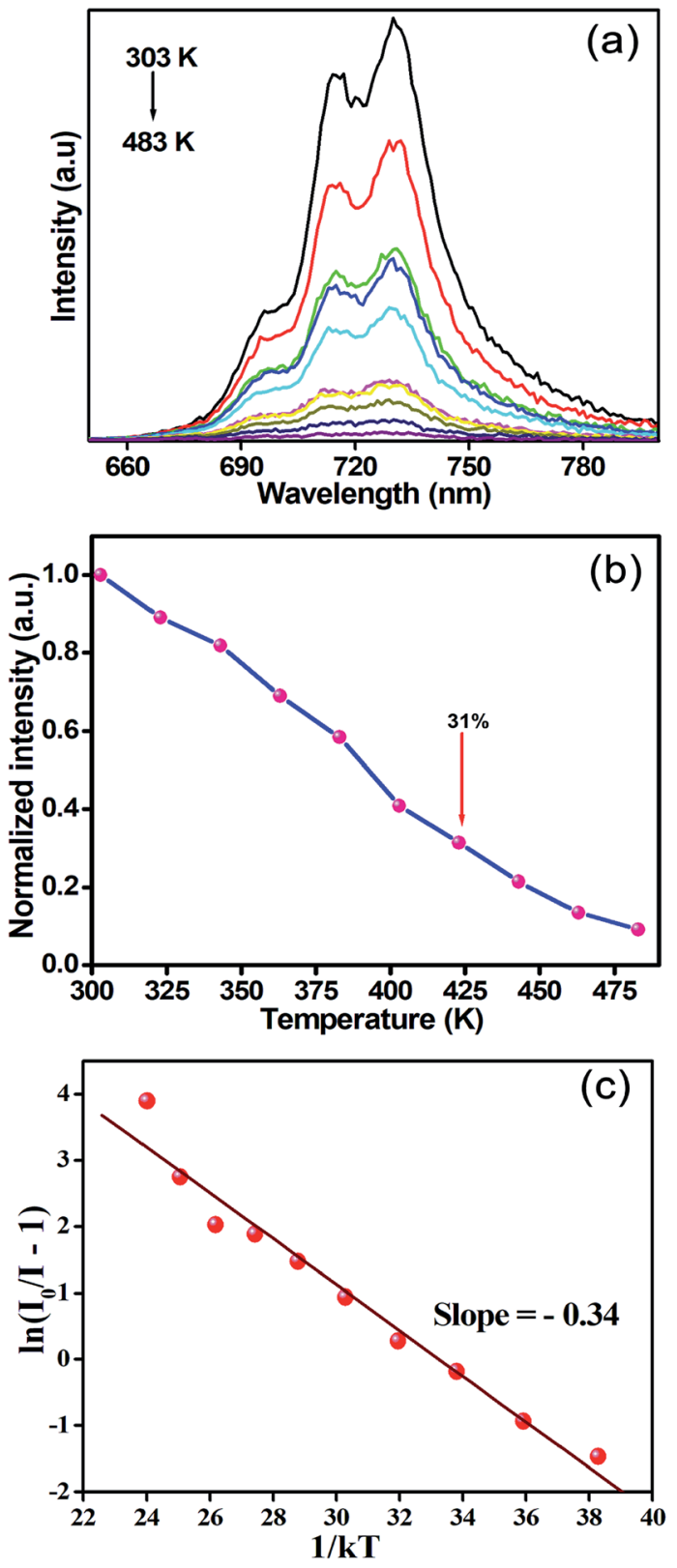

Fig. 7 (a) Temperature dependent PL spectra of SLA:0.4\% $\mathrm{Mn}^{4+}$ phosphors ( $\lambda_{\text {ex }}=364 \mathrm{~nm}$ ). (b) Normalized PL intensity of SLA:0.4\% $\mathrm{Mn}^{4+}$ phosphors as a function of various temperatures. (c) The relationship of $\ln \left(I_{0} / /-1\right)$ versus $1 / k T$ of the SLA: $0.4 \% \mathrm{Mn}^{4+}$ phosphors.

$$
\eta_{\mathrm{QE}}=\frac{\int L_{\mathrm{S}}}{\int E_{\mathrm{R}}-\int E_{\mathrm{S}}}
$$

where $L_{\mathrm{S}}, E_{\mathrm{S}}$ and $E_{\mathrm{R}}$ are the luminescence emission spectrum of the sample, spectrum of the light used for exciting the sample and spectrum of the excitation light without the sample, respectively. The IQE value of the SLA:0.4\% $\mathrm{Mn}^{4+}$ phosphors was measured to be $29 \%$ under the excitation of $364 \mathrm{~nm}$, which was higher than that of $\mathrm{Ca}_{14} \mathrm{Al}_{10} \mathrm{O}_{35}: \mathrm{Mn}^{4+}$ (IQE: 19.4\%), ${ }^{60}$ $\left(\mathrm{NH}_{4}\right)_{2} \mathrm{TiF}_{6}: \mathrm{Mn}^{4+}$ (IQE: 16.4\%), ${ }^{61}$ and $\mathrm{CaMg}_{2} \mathrm{Al}_{16} \mathrm{O}_{27}$ (IQE: 16\%) phosphors, ${ }^{33}$ but smaller than some oxide and fluoride phosphors like $\mathrm{Ca}_{2} \mathrm{YSbO}_{6}: \mathrm{Mn}^{4+}$ (IQE: 62.6\%), ${ }^{62}$ and $\mathrm{Rb}_{2} \mathrm{SiF}_{6}: \mathrm{Mn}^{4+}$ (IQE: $>90 \%){ }^{63}$ 
The thermal behaviour is an important parameter for phosphors in practical application. Fig. 7(a) shows the temperature-dependent PL spectra of SLA:0.4\% $\mathrm{Mn}^{4+}$ deep red emitting phosphors recorded at various temperatures in the range of 303-483 $\mathrm{K}$ under the excitation of $364 \mathrm{~nm}$. Clearly, the PL intensity decreased with increasing of temperature due to the thermal quenching effect. Fig. 7(b) shows the normalized PL intensity of SLA:0.4\% $\mathrm{Mn}^{4+}$ phosphors as a function of various temperatures. It can be clearly seen that the PL intensity at the temperature of $423 \mathrm{~K}$ was found to be about $31 \%$ of that at 303 $\mathrm{K}$, which was better than the reported value of $27 \%$ of $\mathrm{Gd}_{2}$ $\mathrm{ZnTiO}_{6}: \mathrm{Mn}^{4+}$ phosphors. ${ }^{64}$ Furthermore, considerable changes were not found in their spectra, which indicated that the asprepared SLA: $\mathrm{Mn}^{4+}$ phosphors offered low thermal stability due to its charge compensation-related defects induced by the replacement of $\mathrm{Mn}^{4+}$ ion into $\mathrm{Al}^{3+}$ host site (not stable at temperatures above $250 \mathrm{~K}$ ). The activation energy was calculated using Arrhenius equation, which can be explained below as: ${ }^{65}$

$$
I(T)=\frac{I_{0}}{1+c \exp \left(-\frac{\Delta E_{\mathrm{a}}}{k T}\right)}
$$

where $I_{0}$ is the emission intensity at the initial temperature; $I(T)$ is the emission intensity at measured temperature; $c$ is a constant; $k$ is the Boltzmann's constant; and $\Delta E_{\mathrm{a}}$ is the activation energy. Fig. 7 (c) demonstrates the plot of $\ln \left(I_{0} / I-1\right)$ versus $1 / k T$. The experimental values were well linearly fitted with a slope of -0.34 , and thus the activation energy value was $0.34 \mathrm{eV}$.

A deep red emitting LED device was fabricated by using SLA:0.4\% $\mathrm{Mn}^{4+}$ phosphors combined with a $365 \mathrm{~nm}$ emitting InGaN LED chip. The electroluminescence (EL) spectrum of asprepared LED device under $20 \mathrm{~mA}$ and $3.17 \mathrm{~V}$ was shown in Fig. 8. A strong red emission peak at $730 \mathrm{~nm}$ in the wavelength

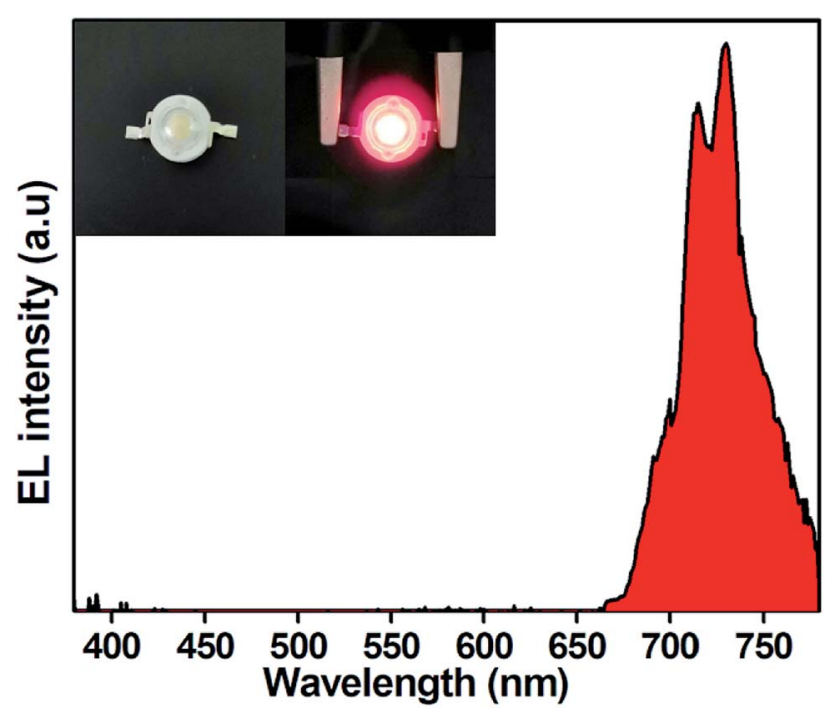

Fig. 8 EL spectrum of the fabricated deep-red LED device using SLA:0.4\% $\mathrm{Mn}^{4+}$ phosphors and a $365 \mathrm{~nm}$ near-UV LED chip under a current of $20 \mathrm{~mA}$. Inset shows the fabricated LED device and corresponding luminescent image. range of 650-800 $\mathrm{nm}$ was observed. The luminous efficacy value of the as-fabricated LED device was $0.09 \mathrm{~lm} \mathrm{~W}^{-1}$. The low luminous efficacy may be attributed to the presence of strong emission peak displayed by SLA:0.4\% $\mathrm{Mn}^{4+}$ phosphors in the deep red spectral region, where the human eye sensitivity is very low. However, the plants are sensitive in the deep red light. Therefore, the SLA:0.4\% $\mathrm{Mn}^{4+}$ phosphors could be used to fabricate deep red-emitting LEDs towards indoor plant cultivation.

\section{Conclusions}

In conclusion, we have successfully synthesized deep red emitting SLA:0.4\% $\mathrm{Mn}^{4+}$ phosphors using conventional hightemperature solid-state reaction method. The role of $\mathrm{Mn}^{4+}$ ions on crystal structure and photoluminescence properties of SLA phosphors was systematically investigated. XRD and Rietveld refinement data proved that the SLA:0.4\% $\mathrm{Mn}^{4+}$ phosphors were indexed by tetragonal crystal system. The SLA:0.4\% $\mathrm{Mn}^{4+}$ phosphors exhibited deep red emission peaking at $730 \mathrm{~nm}$ under the excitation of $364 \mathrm{~nm}$, and the resultant CIE coordinate values were $(0.734,0.266)$. The critical energy transfer distance of these phosphors was calculated to be $35.48 \AA$ and the concentration quenching mechanism was confirmed to be the $\mathrm{d}-\mathrm{d}$ interaction between $\mathrm{Mn}^{4+}$ ions. Decay lifetime values of SLA: $x \mathrm{Mn}^{4+}$ phosphors gradually decreased with increasing of $\mathrm{Mn}^{4+}$ concentration. Meanwhile, the SLA:0.4\% $\mathrm{Mn}^{4+}$ deep red phosphors also exhibited proper thermal stability, in addition, a deep-red LED device was fabricated using a $365 \mathrm{~nm}$ InGaN chip combined with the SLA:0.4\% $\mathrm{Mn}^{4+}$ red emitting phosphors. The results indicated SLA:0.4\% $\mathrm{Mn}^{4+}$ phosphors would be promising candidate as a deep red phosphor for plant cultivation LEDs applications.

\section{Conflicts of interest}

There are no conflicts to declare.

\section{Acknowledgements}

The present research work was supported by the National Natural Science Foundation of China (No. 51502190), the Program for the Outstanding Innovative Teams of Higher Learning Institutions of Shanxi, and the Open Fund of the State Key Laboratory of Luminescent Materials and Devices (South China University of Technology, No. 2017-skllmd-01).

\section{Notes and references}

1 M. Chen, Z. Xia and Q. Liu, J. Mater. Chem. C, 2015, 3, 41974204.

2 S.-P. Lee, T.-S. Chan and T.-M. Chen, ACS Appl. Mater. Interfaces, 2014, 7, 40-44.

3 R. Cao, D. Peng, H. Xu, S. Jiang, Z. Luo, H. Ao and P. Liu, J. Lumin., 2016, 178, 388-391.

4 N. Zhang, C. Guo, L. Yin, J. Zhang and M. Wu, J. Alloys Compd., 2015, 635, 66-72. 
5 X. Huang, Nat. Photonics, 2014, 8, 748-749.

6 P. Du, Y. Guo, S. H. Lee and J. S. Yu, RSC Adv., 2017, 7, 31703178.

7 B. Li, X. Huang, H. Guo and Y. Zeng, Dyes Pigm., 2018, 150, 67-72.

8 X. Huang, J. Alloys Compd., 2017, 690, 356-359.

9 X. Huang, B. Li and H. Guo, J. Alloys Compd., 2017, 695, 2773-2780.

10 P. Du, X. Huang and J. S. Yu, Inorg. Chem. Front., 2017, 4, 1987-1995.

11 P. Du, X. Huang and J. S. Yu, Chem. Eng. J., 2018, 337, 91-100.

12 Q. Sun, S. Wang, B. Li, H. Guo and X. Huang, J. Lumin., 2018, 203, 371-375.

13 X. Huang, S. Wang, B. Li, Q. Sun and H. Guo, Opt. Lett., 2018, 43, 1307-1310.

14 X. Huang, B. Li, H. Guo and D. Chen, Dyes Pigm., 2017, 143, 86-94.

15 P. Du, L. Luo, X. Huang and J. S. Yu, J. Colloid Interface Sci., 2018, 514, 172-181.

16 G. Tamulaitis, P. Duchovskis, Z. Bliznikas, K. Breive, R. Ulinskaite, A. Brazaityte, A. Novičkovas and A. Žukauskas, J. Phys. D: Appl. Phys., 2005, 38, 3182-3187.

17 M. Olle and A. Viršile, Agric. Food Sci., 2013, 22, 223-234.

18 G. D. Massa, H.-H. Kim, R. M. Wheeler and C. A. Mitchell, HortScience, 2008, 43, 1951-1956.

19 J. Chen, N. Zhang, C. Guo, F. Pan, X. Zhou, H. Suo, X. Zhao and E. M. Goldys, ACS Appl. Mater. Interfaces, 2016, 8, 2085620864.

20 N. Yeh, T. J. Ding and P. Yeh, Renewable Sustainable Energy Rev., 2015, 51, 55-61.

21 C. Koc, G. A. Anderson and A. Kommareddy, Isr. J. Aquac., 2013, 65, 797-805.

22 H. G. Choi, B. Y. Moon and N. J. Kang, Sci. Hortic., 2015, 189, 22-31.

23 C.-W. Yeh, W.-T. Chen, R.-S. Liu, S.-F. Hu, H.-S. Sheu, J.-M. Chen and H. T. Hintzen, J. Am. Chem. Soc., 2012, 134, 14108-14117.

24 X. Zhang, L. Zhou, Q. Pang, J. Shi and M. Gong, J. Phys. Chem. $C$, 2014, 118, 7591-7598.

25 H. Li, R. Zhao, Y. Jia, W. Sun, J. Fu, L. Jiang, S. Zhang, R. Pang and C. Li, ACS Appl. Mater. Interfaces, 2014, 6, 3163-3169.

26 X. Huang, H. Guo and B. Li, J. Alloys Compd., 2017, 720, 2938.

27 X. Huang, B. Li, P. Du, H. Guo, R. Cao, J. S. Yu, K. Wang and X. W. Sun, Dyes Pigm., 2018, 151, 202-210.

28 H. Zhu, C. C. Lin, W. Luo, S. Shu, Z. Liu, Y. Liu, J. Kong, E. Ma, Y. Cao, R.-S. Liu and X. Chen, Nat. Commun., 2014, 5, 4312-4317.

29 S. Okamoto and H. Yamamoto, J. Electrochem. Soc., 2010, 157, J59-J63.

30 M. Peng, X. Yin, P. A. Tanner, C. Liang, P. Li, Q. Zhang and J. Qiu, J. Am. Ceram. Soc., 2013, 96, 2870-2876.

31 Y. Tanabe and S. Sugano, J. Phys. Soc. Jpn., 1954, 9, 766-779.

32 X. Huang, J. Liang, B. Li, L. Sun and J. Lin, Opt. Lett., 2018, 43, 3305-3308.

33 B. Wang, H. Lin, J. Xu, H. Chen and Y. Wang, ACS Appl. Mater. Interfaces, 2014, 6, 22905-22913.
34 M. Brik, S. Camardello and A. Srivastava, ECS J. Solid State Sci. Technol., 2015, 4, R39-R43.

35 S. Zhang, Y. Hu, H. Duan, L. Chen, Y. Fu, G. Ju, T. Wang and M. He, $R S C A d v$. , 2015, 5, 90499-90507.

36 R. Cao, W. Luo, Q. Xiong, A. Liang, S. Jiang and Y. Xu, J. Alloys Compd., 2015, 648, 937-941.

37 T. Sasaki, J. Fukushima, Y. Hayashi and H. Takizawa, Chem. Lett., 2014, 43, 1061-1063.

38 Y. Zhydachevskii, A. Suchocki, A. Pajączkowska, A. Kłos, A. Szysiak and A. Reszka, Opt. Mater., 2013, 35, 1664-1668. 39 S. Adachi, J. Lumin., 2018, 197, 119-130.

40 S. Adachi, J. Lumin., 2018, 202, 263-281.

41 X. Huang and H. Guo, Dyes Pigm., 2018, 152, 36-42.

42 Q. Sun, B. Li, S. Wang, H. Guo and X. Huang, J. Mater. Sci.: Mater. Electron., 2018, 29, 12972-12977.

43 J. Liang, L. Sun, B. Devakumar, S. Wang, Q. Sun, H. Guo, B. Li and X. Huang, RSC Adv., 2018, 8, 27144-27151.

44 Q. Sun, S. Wang, B. Devakumar, B. Li, L. Sun, J. Liang and X. Huang, RSC Adv., 2018, 8, 28538-28545.

45 K. Li, H. Lian and R. Van Deun, J. Lumin., 2018, 198, 155-162. 46 K. Li, H. Lian and R. Van Deun, Dalton Trans., 2018, 47, 2501-2505.

47 B. Liu, L. Li, X. Q. Liu and X. M. Chen, J. Mater. Chem. C, 2016, 4, 4684-4691.

48 A. Bergstein and W. B. White, J. Electrochem. Soc., 1971, 118, 1166-1171.

49 Y. Pan and G. Liu, Opt. Lett., 2008, 33, 1816-1818.

50 Y. Zhang, X. Li, K. Li, H. Lian, M. Shang and J. Lin, ACS Appl. Mater. Interfaces, 2015, 7, 2715-2725.

51 H. Y. Jiao and Y. Wang, Physica B, 2012, 407, 2729-2733.

52 A. Srivastava and M. Brik, J. Lumin., 2012, 132, 579-584.

53 R. Cao, Q. Xiong, W. Luo, D. Wu, X. Fen and X. Yu, Ceram. Int., 2015, 41, 7191-7196.

54 G. Blasse, J. Solid State Chem., 1986, 62, 207-211.

55 L. Van Uitert, J. Electrochem. Soc., 1967, 114, 1048-1053.

56 Z. Xia, H. Liu, X. Li and C. Liu, Dalton Trans., 2013, 42, 16588-16595.

57 G. Y. Lee, J. Y. Han, W. B. Im, S. H. Cheong and D. Y. Jeon, Inorg. Chem., 2012, 51, 10688-10694.

58 J. Y. Han, W. B. Im, G.-y. Lee and D. Y. Jeon, J. Mater. Chem., 2012, 22, 8793-8798.

59 T. Wei, Q. Ren, X. Wu, X. Shi, B. Wang and Z. Huo, Opt. Laser Technol., 2016, 85, 7-13.

60 L. Li, Y. Pan, Z. Chen, S. Huang and M. Wu, RSC Adv., 2017, 7, 14868-14875.

61 L. Xi, Y. Pan, S. Huang and G. Liu, RSC Adv., 2016, 6, 7625176258.

62 J. Zhong, D. Chen, X. Chen, K. Wang, X. Li, Y. Zhu and Z. Ji, Dalton Trans., 2018, 47, 6528-6537.

63 S. Sakurai, T. Nakamura and S. Adachi, ECS J. Solid State Sci. Technol., 2016, 5, R206-R210.

64 H. Chen, H. Lin, Q. Huang, F. Huang, J. Xu, B. Wang, Z. Lin, J. Zhou and Y. Wang, J. Mater. Chem. C, 2016, 4, 2374-2381.

65 H. Guo, X. Huang and Y. Zeng, J. Alloys Compd., 2018, 741, 300-306. 